\title{
DNA methylation is a common molecular alteration in colorectal cancer cells and culture method has no influence on DNA methylation
}

\author{
SHIBAO WANG ${ }^{1}$, YINGHUI HUANG ${ }^{2}$, XUPENG MU $^{2}$, TIANYANG $\mathrm{QI}^{2}$, \\ SHA QIAO ${ }^{1}$, ZHENXIA LU ${ }^{1}$ and HONGJUN LI ${ }^{3}$ \\ ${ }^{1}$ Department of Oncology and Hematology; ${ }^{2}$ Science Research Center; ${ }^{3}$ Physical Examination Center, \\ China-Japan Union Hospital, Jilin University, Changchun, Jilin 130033, P.R. China
}

Received May 23, 2016; Accepted April 21, 2017

DOI: 10.3892/etm.2018.5809

\begin{abstract}
The present study aimed to explore whether culture method had an influence on DNA methylation in colorectal cancer (CRC). In the present study, CRC cells were cultured in two-dimensional (2D), three-dimensional (3D) and mouse orthotopic transplantation (Tis) cultures. Principal component analysis (PCA) was used for global visualization of the three samples. A Venn diagram was applied for intersection and union analysis for different comparisons. The methylation condition of 5'-C-phosphate-G-3' (CpG) location was determined using unsupervised clustering analysis. Scatter plots and histograms of the mean $\beta$ values between 3D vs. 2D, $3 \mathrm{D}$ vs. Tis and Tis vs. $2 \mathrm{D}$ were constructed. In order to explore the biological function of the genes, gene ontology and Kyoto Encyclopedia of Gene and Genomes (KEGG) pathway analyses were utilized. To explore the influence of culture condition on genes, quantitative methylation specific polymerase chain reaction (QMSP) was performed. The three samples connected with each other closely, as demonstrated by PCA. Venn diagram analysis indicated that some differential methylation positions were commonly shared in the three groups of samples and $16 \mathrm{CpG}$ positions appeared hypermethylated in the three samples. The methylation patterns between the 3D and 2D cultures were more similar than those of 3D and Tis, and Tis and 2D. Results of gene ontology demonstrated that differentially expressed genes were involved in molecular function, cellular components and biological function. KEGG analysis indicated that genes were enriched in 13 pathways, of which four pathways were the most evident. These pathways were pathways in cancer, mitogen-activated protein kinase
\end{abstract}

Correspondence to: Dr Hongjun Li, Physical Examination Center, China-Japan Union Hospital, Jilin University, 126 Xiantai Street, Changchun, Jilin 130033, P.R. China

E-mail: lihongjun1030@126.com

Key words: colorectal cancer,DNA methylation, 5'-C-phosphate-G-3', culture method signaling, axon guidance and insulin signaling. Furthermore, QMSP demonstrated that methylation of mutL homolog, phosphatase and tensin homolog, runt-related transcription factor, Ras association family member, cadherin-1, O-6-methylguanine-DNA-methyltransferase and P16 genes had no obvious difference in 2D,3D and Tis culture conditions. In conclusion, the culture method had no influence on DNA methylation in CRC cells.

\section{Introduction}

Colorectal cancer (CRC), originating from the epithelial lining of the large bowel (1), is a malignant neoplasm containing colon and rectal cancer. Its morbidity rate has increased rapidly over the last 30 years in many countries, including China, Japan and Spain (2). The treatment of CRC predominantly includes surgery, chemotherapy, radiation therapy, biological therapy and the combinational therapy; however, these treatments are not always entirely effective and so CRC often has a poor prognosis $(3,4)$. The development of CRC is a multistage and complex process, as with the majority of malignant tumors. The mechanisms involved in the development of CRC are not fully understood and have attracted the interest of many researchers (5). P16 is a tumor suppressor that has a key influence in many diseases, including CRC (6). The hypermethylation of P16 has been demonstrated to have a key role in carcinogenesis (7). The occurrence of CRC is reported to result from a position named 'field defect'; however, this mechanism is not well known (8). It has been reported that DNA methylation may have a role in mediating the field defect (8). In CRC cells, alterations to DNA methylation has an important influence (9). However, the molecular mechanism of how DNA hypermethylated genes influence the development of cancer has not been fully elucidated.

To study the varied processes in cancer, such as the inactivation of the $\mathrm{X}$ chromosome and the silencing of tumor-related genes, it is necessary to understand the details of DNA methylation in 5'-C-phosphate-G-3' (CpG) regions (10). $\mathrm{CpG}$ islands are often made up of gene promoters or exons (11). However, these islands are often unmethylated in normal cells, and methylation of $\mathrm{CpG}$ regions may affect 
condensed chromatin (12). CpG regions often have roles in promoting DNA replication origins, which are fundamental to chromosome organization and duplication (13). They are bimodal and enriched at $\mathrm{CpG}$ islands in mouse and Drosophila. (14). Research has demonstrated that there are often some molecular abnormalities in tumor tissues and adjacent tissues, despite them appearing histologically normal (15). The occurrence of these abnormalities in the adjacent tissues is named 'field defect' (16). Research has indicated that higher DNA methylation levels of Ras association family member (RASSF) 1A, adenomatous polyposis coli and human mutL homolog (MLH) exist in CRC than in adjacent tissues (17).

Three-dimensional (3D) cell culture systems as a tumor model in vitro is a vital tool in research of DNA methylation (18). In 3D cultured pluripotent stem cells, DNA methylation was changed and some genes were upregulated (19). However, it is not known whether the culture method affects the DNA methylation in $\mathrm{CpG}$ regions in $\mathrm{CRC}$ cells. The present study aimed to identify the relationship between DNA methylation and CRC, and the influence of culture method on DNA methylation.

\section{Materials and methods}

Cell culture. CRC cell line, DLD-1, was purchased from Renmin Hospital of Hubei University of Medicine (Shiyan, China). DLD-1 cells were routinely cultivated in RPMI-1640 (Gibco; Thermo Fisher Scientific, Inc., Waltham, MA, USA) supplemented with $10 \%$ heat-inactivated fetal bovine serum (FBS; Gibco; Thermo Fisher Scientific, Inc.), 100 U/ml penicillin and $100 \mu \mathrm{g} / \mathrm{ml}$ streptomycin at two-dimensional (2D), $3 \mathrm{D}$ and orthotopic transplantation (Tis) stages in a humidified cell incubator $\left(5 \% \mathrm{CO}_{2}\right)$ at $37^{\circ} \mathrm{C} .2 \mathrm{D}$ culture refers to DLD-1 culture in RPMI-1640 supplemented with 10\% FBS in a common culture dish. 3D culture refers to the culture of DLD-1 cells in suspension in RPMI-1640 free of FBS in a culture plate containing Matrigel, which was used to distribute the signal cells. This means that DLD-1 cells were inoculated into 20 nude rats (age, 6 months; weight, 100-150 g; Animal Center of Shandong University, Jinan, China) as previously described (20) to establish a xenograft animal model. The ratio of male to female rats was $1: 1$. Rats were housed at an ambient temperature of $20-22^{\circ} \mathrm{C}$ with a relative humidity of $50 \pm 5 \%$ and a $12 \mathrm{~h}$ light/dark cycle. The rats were allowed free access to food and water until the next procedure was performed. Following the formation of an orthotopic colorectal tumor, after 14 days, rats were sacrificed by cervical dislocation under $1 \%$ pentobarbital sodium anesthesia (40 mg/kg; Sigma-Aldrich; Merck KGaA, Darmstadt, Germany). Tumor tissue was harvested, cut into small pieces and rapidly frozen in liquid nitrogen. The present study was approved by the Institutional Animal Care and Use Committee of Jilin University (Changchun, China).

Total RNA isolation and methylation chip genome-wide detection. An RNeasy mini kit (Qiagen, Inc., Valencia, CA, USA) was used to isolate total RNA from rat tissues, according to the manufacturer's instructions. The reverse transcription reaction was carried out with TaqMan MicroRNA Reverse Transcription kit (Applied Biosystems; Thermo Fisher Scientific, Inc., Waltham, MA, USA) in $15 \mu \mathrm{l}$ containing $5 \mu \mathrm{l}$
RNA extract, $0.15 \mu 1100 \mathrm{mM}$ dNTPs, $1 \mu 1$ Multiscribe Reverse Transcriptase $(50 \mathrm{U} / \mu \mathrm{l}), 1.5 \mu \mathrm{l} 10 \mathrm{x}$ reverse transcription buffer, $0.19 \mu \mathrm{l}$ RNase inhibitor $(20 \mathrm{U} / \mu \mathrm{l}), 1 \mu \mathrm{l}$ of gene-specific primer and $4.16 \mu \mathrm{l}$ of nuclease-free water. For synthesis of cDNA, the reaction mixtures were incubated at $16^{\circ} \mathrm{C}$ for $30 \mathrm{~min}$, $42^{\circ} \mathrm{C}$ for $30 \mathrm{~min}, 85^{\circ} \mathrm{C}$ for $5 \mathrm{~min}$ and stored at $4^{\circ} \mathrm{C}$. A total of $1.33 \mu \mathrm{l}$ cDNA solution was amplified using $10 \mu \mathrm{l}$ of TaqMan 2X Universal polymerase chain reaction (PCR) Master Mix with no AmpErase UNG (Applied Biosystems; Thermo Fisher Scientific, Inc.), $1 \mu \mathrm{l}$ gene-specific primers/probe and $7.67 \mu 1$ of nuclease-free water in a final volume of $20 \mu \mathrm{l}$. Quantitative PCR (TaqMan) analysis was performed on a TaqMan ABI Prism 7000 Sequence Detection System (Applied Biosystems; Thermo Fisher Scientific, Inc.). The reaction mixtures were incubated at $95^{\circ} \mathrm{C}$ for $10 \mathrm{~min}$, followed by 40 cycles of $95^{\circ} \mathrm{C}$ for $15 \mathrm{sec}$ and $60^{\circ} \mathrm{C}$ for $1 \mathrm{~min}$. The relative expression was normalized to the expression of $\beta$-actin (forward, 5'-ACA GAGCCTCGCCTTTGC-3' and reverse, 5'-GCGGCGATA TCATCATCC-3'). Relative fold changes of gene expression were calculated by the $2^{-\Delta \Delta \mathrm{Cq}}$ method $(21,22)$. The methylation primer was as follows: Forward, 5'-CGTTTTATTTCGGTT TTGTTTTC-3' and reverse, 5'-CTCGAAATTTAATAAAAA CTTCACG-3'. The amplified DNA was cut into segments by restriction endonuclease (Bethesda Research Laboratories, Inc., Gaithersburg, MD, USA) and the DNA fragments were precipitated by precipitation solution PM1 (Promega Corp., Madison, WI, USA) and isopropanol (Sigma-Aldrich; Merck KGaA). The sedimentary DNA was suspended again in precipitation solution PM1 and isopropanol. The resuspended DNA samples were dispersed on beadchip chips and Human HT-12 v. 4.0 BeadChip (Illumina, Inc., San Diego, CA, USA) was used for hybridization. Illumina iScan 148 (Illumina, Inc.) was applied to image the BeadChips. Before using this, Illumina data were reserved on the basis of the Minimum Information about a Microarray Experiment guidelines in the public Gene Expression Omnibus database (ncbi.nlm.nih. gov/geo/), accession number GSE 54690.

DNA extraction and quantitative methylation specific PCR $(Q M S P)$. A Multisource Genomic DNA Miniprep kit (Axygen Scientific; Thermo Fisher Scientific, Inc.) was applied to extract total DNA from DLD-1 cells, according to the recommendations of manufacturer. A CpGenome ${ }^{\mathrm{TM}}$ DNA Modification kit (Chemicon; Merck KGaA) was employed to modify each genomic DNA from samples using sodium bisulfate according to the manufacturer's protocol. The methylation levels of MLH, phosphatase and tensin homolog (PTEN), runt-related transcription factor (RUNX), RASSF, cadherin-1 (CDH1), O-6-methylguanine-DNA-methyltransferase (MGMT) and P16 were determined. The regions of $\beta$-actin that were short of any $\mathrm{CpG}$ dinucleotide were amplified using a Cyclogene thermal cycler machine (Techne, Cambridge, UK): $65^{\circ} \mathrm{C}$ for $5 \min , 96^{\circ} \mathrm{C}$ for $2 \min , 65^{\circ} \mathrm{C}$ for $4 \min , 96^{\circ} \mathrm{C}$ for $1 \mathrm{~min}, 65^{\circ} \mathrm{C}$ for $1 \mathrm{~min}$, and $96^{\circ} \mathrm{C}$ for $30 \mathrm{sec}$. The primers used were as follows: MLH forward 5'-GGTTGGATATTTYGTATTTTTYGA G-3' and reverse 5'-AATTACTAAATCTCTTCRTCCCTC C-3'; RUNX forward, 5'-CCTTACGTAGAGGTCACAGTA G-3' and reverse 5'-CTCCAAGCTGCAAAGTCAC-3'; CDH1 forward, 5'-AATTTTAGGTTAGAGGGTTATCGCGT-3' and reverse, 5'-TCCCCAAAACGAAACTAACGAC-3'; MGMT 
forward, 5'-GGGTTATTTGGTAAATTAAGGTATAGAG-3' and reverse, 5'-CACCTAAAAATAAAACAAAAACTACCA C-3'; P16 forward, 5'-GAGGGGGTAGGGGGATAT-3' and reverse, 5'-ACCAATCAACCAAAAACTCCATACTA-3'; $\beta$-actin forward, 5'-ACAGAGCCTCGCCTTTGC-3' and reverse, 5'-GCGGCGATATCATCATCC-3'.

Analysis of differential gene transcription. Principal component analysis (PCA) may be used to analyze data tables whose content contains some inter-correlated quantitative dependent variables. Partek Genomics Suite v. 6.5 (Partek, Inc., St Louis, MO, USA) was used to analyze the gene expression data. The analyzed data were then corrected and normalized by quantile normalization and summarization (23). PCA was used for global visualization of all datasets.

Functional enrichment and pathway enrichment analysis. MetaCore Bioinformatics software (www.portal.genego. $\mathrm{com} /$ ) was used to identify the significant pathways. Data for Annotation, Visualization, and Integrated Discovery (DAVID; (http://david.niaid.nih.gov), ) was used to conduct Gene Ontology (GO; http://www.geneontology.org/) and Kyoto Encyclopedia of Genes and Genomes (KEGG; http://www. genome.jp/kegg/ or http://www.kegg.jp/) pathway enrichment analysis. DAVID is able to combine integrate functional genomic annotations with intuitive graphical summaries. This contributed to the explanation on genome-scale datasets by promoting the change from data collection to biological meaning. GO terms and KEGG pathways with $\mathrm{P}<0.01$ were selected (24). The P-values were calculated as follows:

$$
p=\frac{\left(\begin{array}{c}
a+b \\
a
\end{array}\right)\left(\begin{array}{c}
c+d \\
c
\end{array}\right)}{\left(\begin{array}{c}
n \\
a+c
\end{array}\right)}
$$

Where, $\mathrm{n}$ is the number of background genes; $a^{\prime}$ is the gene number of one gene set in the gene lists; $a^{\prime}+b$ is the number of genes in the gene list and one gene set was also included; $a^{\prime}+c$ is the gene number of one gene list in the background genes; and $a^{\prime}$ is replaced with $a=a^{\prime}-1$.

Statistical analysis. Scatter plots of the genome-wide methylation changes in Tamoxifen-resistant lines and parental was performed. SPSS v. 19.0 (IBM Corp., Armonk, NY, USA) and GraphPad Prism 6 (GraphPad Software, Inc., La Jolla, CA, USA) software were employed to analyze data. Two sample t-tests were used to differentiate the mean methylation scores between two samples. A paired t-test was applied to determine the differences of average sib pair in methylation scores. $\mathrm{P}<0.05$ was considered to indicate a statistically significant difference.

\section{Results}

Analysis of differential gene transcription. Partek Genomics Suite v. 6.5 was used to analyze the gene expression data. The analyzed data were then corrected and normalized by quantile normalization and summarization. The datasets were deposited for CRC cells (DLD-1) in 2D, 3D and Tis stages. PCA was used for global visualization of all datasets (Fig. 1A). PCA is one of the most important and powerful methods in chemometrics as well as in a wealth of other areas (25). It is a one-sample technique applied to data with no groupings among the observations and no partitioning of the variables into sub-vectors $y$ and $x$ (26). PCA analysis revealed the close connection between the DLD1-3D, DLD1-2D and DLD1-Tis groups. Gene lists were established with a cut-off of relative \pm 1.5 -fold change and $\mathrm{P} \leq 0.05$. A Venn diagram of modulated samples in the DLD1-3D, DLD1-2D and DLD1-Tis groups was created. The result demonstrated that 23 genes were commonly found in the DLD1-3D vs. DLD1-2D group, DLD1-3D vs. DLD1-Tis group and DLD1-Tis vs. DLD1-2D group. Apart from the common 23 genes, 95 genes were commonly identified in the DLD1-3D vs. DLD1-2D group and DLD1-Tis vs. DLD1-2D group, 44 genes were commonly identified in the DLD1-3D vs. DLD1-2D group and DLD1-3D vs. DLD1-Tis group, and 18,912 genes were commonly identified in the DLD1-3D vs DLD1-Tis group and DLD1-Tis vs. DLD1-2D group (Fig. 1B). Furthermore, results demonstrated that the overlapping section in the three populations of samples presented high methylation. Unsupervised clustering analysis of the $\mathrm{CpG}$ location revealed that 119 CpGs presented different levels of methylation in the three groups of samples and $16 \mathrm{CpGs}$ all appeared with a highly methylated status in the three groups of samples (Fig. 1C).

Analysis on different $C p G s$. To analyze the different $\mathrm{CpG}$ locations in CRC cells cultured in 2D, 3D and Tis stage cultures, scatter plots were created to compare all $\mathrm{CpG}$ sites among the DLD1-3D, DLD1-2D and DLD1-Tis groups (Fig. 2). The areas outlined in grey on each of the scatter plots in Fig. 2A-C included data points for demethylated $\mathrm{CpG}$ sites that demonstrated a 2-fold change and had average $\beta$ values of $>0.2$. The methylation patterns between DLD1-3D and DLD1-2D (Fig. 2A) were more similar than those of DLD1-3D and DLD1-Tis (Fig. 2B), and DLD1-Tis and DLD1-2D (Fig. 2C). Fig. 2D-F demonstrated the column distribution of $\beta$ values in the three groups of samples. AVG_ $\beta>0.2$ stated that the degree of methylation differences was large.

Functional analysis of differentially methylated DNA. To identify the biological function, cellular component and molecular function of the genes identified, GO and pathway analysis were utilized. From GO, it was demonstrated that there were differentially expressed genes in various over-represented cellular processes. In terms of biological process, DNA-dependent transcription, apoptosis, ion transport, cell differentiation and transmembrane transport were identified to be very important. In terms of cellular components, membrane fraction, cytosol, integral to plasma membrane, perinuclear region of cytoplasm and cytoskeleton were demonstrated to be important. As for molecular function, there were some key functions identified, including signal transducer activity, adenosine 5'-triphosphate binding, calcium ion binding, protein homedimerization activity and nucleotide binding (Fig. 3A). To further refine the biological functions of genes corresponding by differential methylation sites, these genes were placed into cellular or metabolic pathways, based on their roles. KEGG may be used to systematically analyze gene functions based 
A

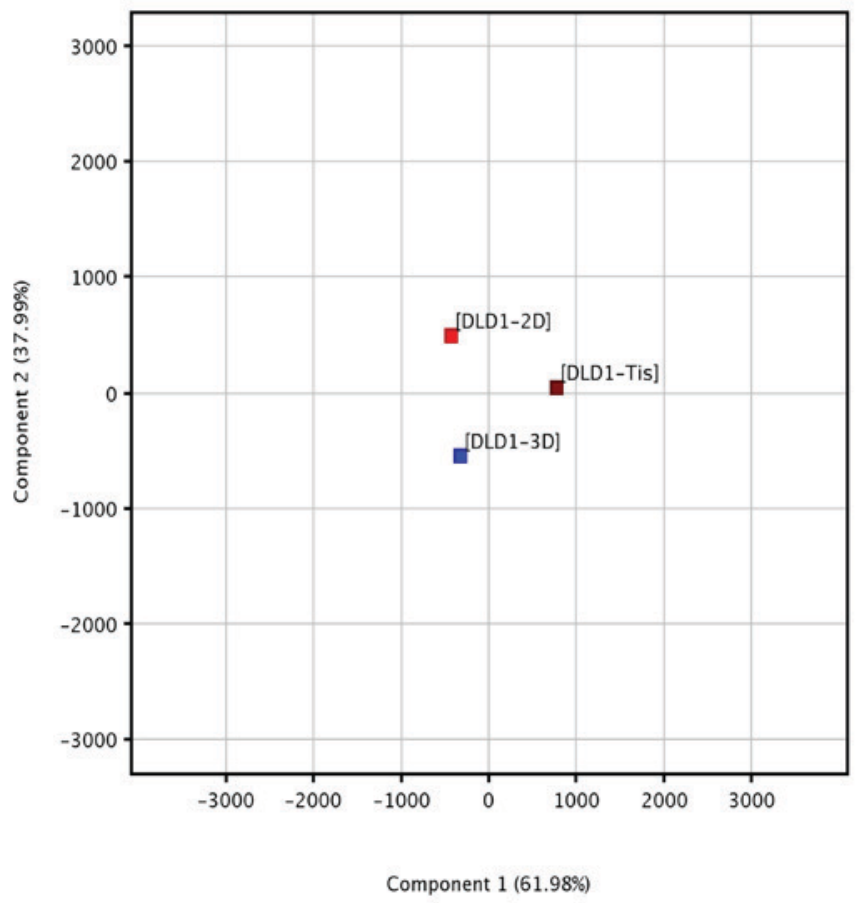

B

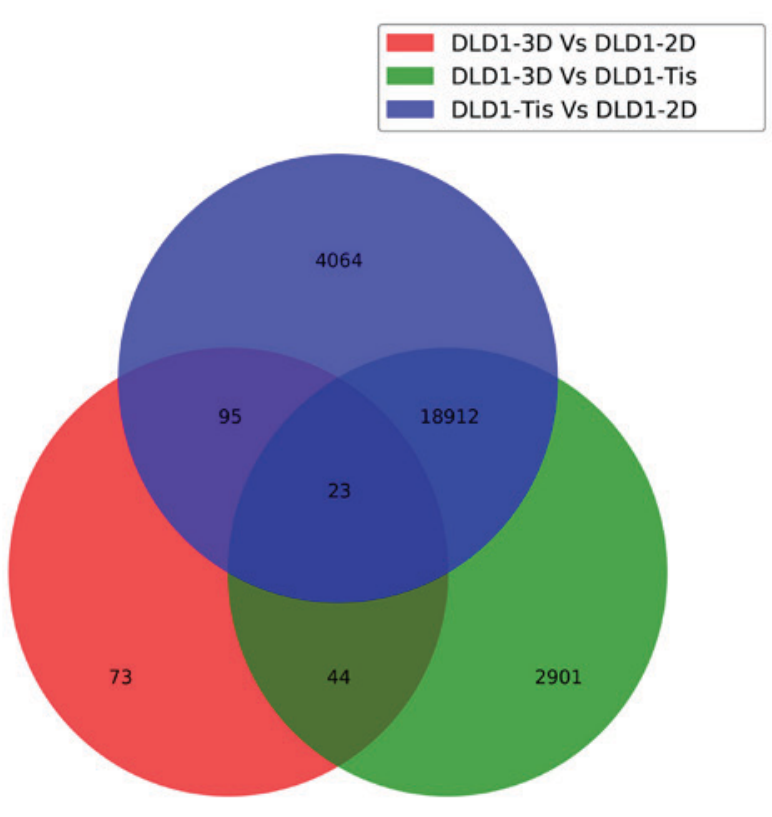

$\mathrm{C}$

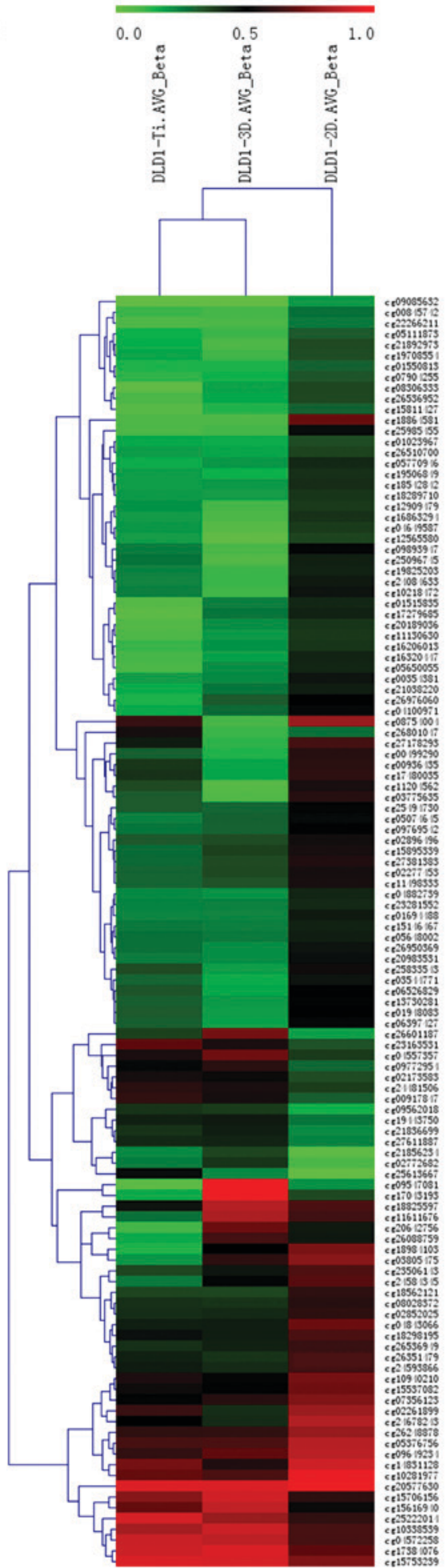

Figure 1. (A) Principal component analysis of dataset. The DLD1-3D, DLD1-2D and DLD1-Tis dataset were analyzed to identify the outlier of the sample group. (B) Venn diagram of differentially methylated DNA. (C) Unsupervised clustering analysis of the 5'-C-phosphate-G-3' locations. The color gradient green to red displays the $\beta$-value and can range from $0-1.3 \mathrm{D}$, three-dimensional culture; $2 \mathrm{D}$, two-dimensional culture; Tis, mouse orthotopic transplantation culture.

on the networks of genes and molecules. Pathway analyses of the corresponding genes recognized 13 significantly over-represented cellular pathways ( $\mathrm{P}=0.032$; Fig. 3B). Among these 13 pathways, four pathways were more significant than the others $(\mathrm{P}=0.008)$. These pathways were cancer pathways, the mitogen-activated protein kinase (MAPK) signaling pathway, axon guidance and the insulin signaling pathway.
Culture condition has no effect on methylation. To determine whether different cell culture methods affected important genes, a QMSP experiment was used. It has been reported that PTEN has a role in regulating the formation of tumors, and its sequence was similar to cytoskeletal protein tensin (27). RUNX genes have been identified as tumor suppressors or oncogenes based on their roles in regulating cell fate and their 
A
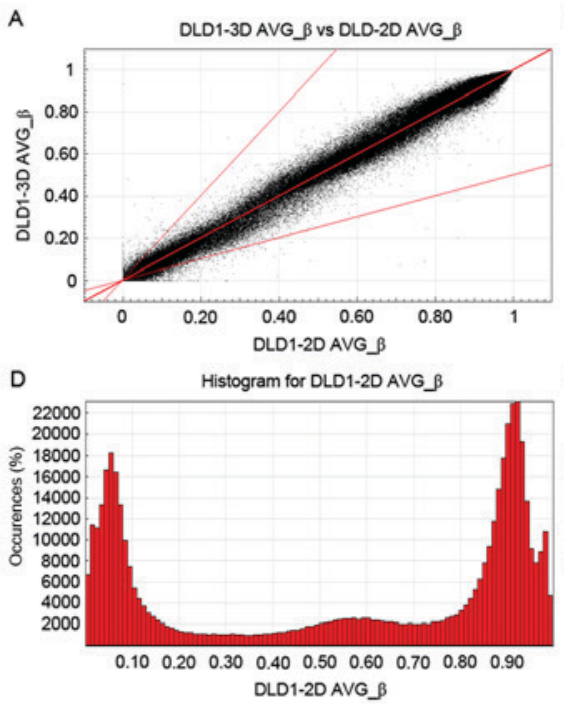

B

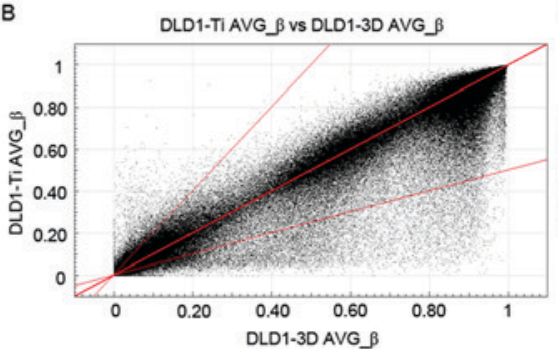

E

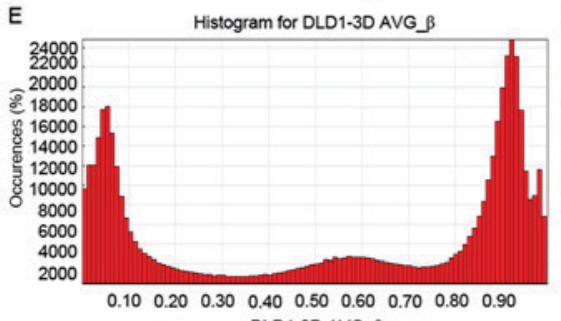

DLD1-2D AVG_
C

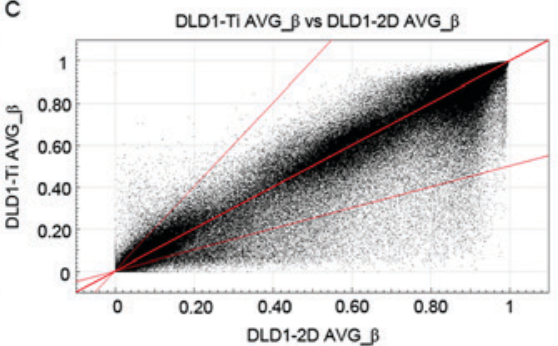

$\mathrm{F}$

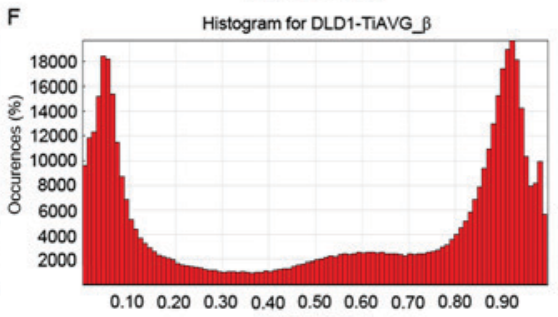

DLD1-TIAVG $\beta$

Figure 2. Scatter plots indicate genome-wide methylation changes in Tamoxifen-resistant lines compared with the parental. (A) DLD1-3D vs. DLD1-2D, (B) DLD1-Tis vs. DLD1-3D and (C) DLD1-Tis vs. DVLD1-2D were compared using GenomeStudio to determine the overall changes in methylation. The black data points mark the average $\beta$ cut-off value of 0.2 for each sample; center red line represents equal $\beta$ values in the two samples; outer red lines mark the 2-fold change in average $\beta$ values for each sample. Column distribution of $\beta$ values in the (D) DLD1-2D, (E) DLD1-3D and (F) DLD1-Tis groups. 3D, three-dimensional culture; 2D, two-dimensional culture; Tis, mouse orthotopic transplantation culture.

A

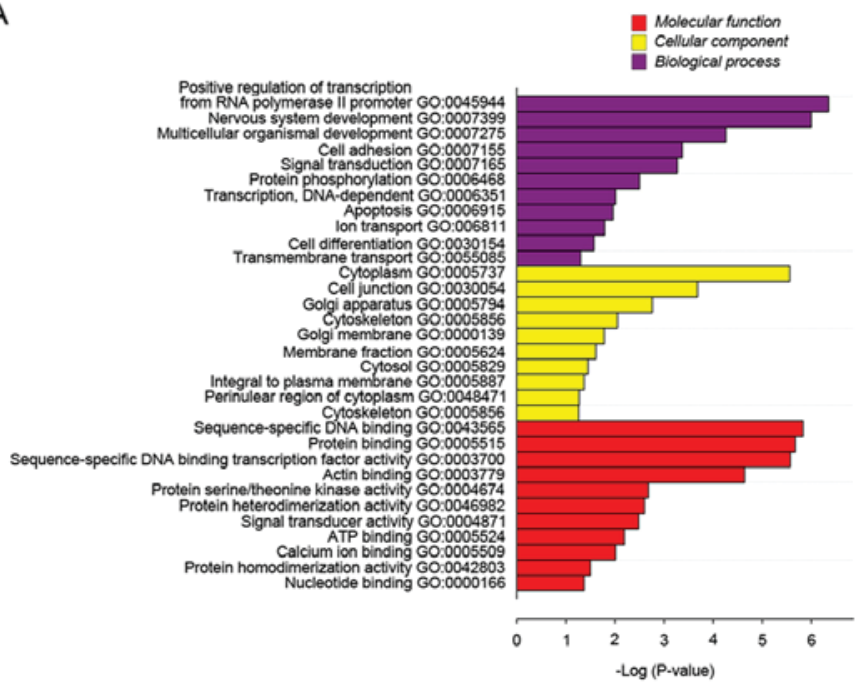

B

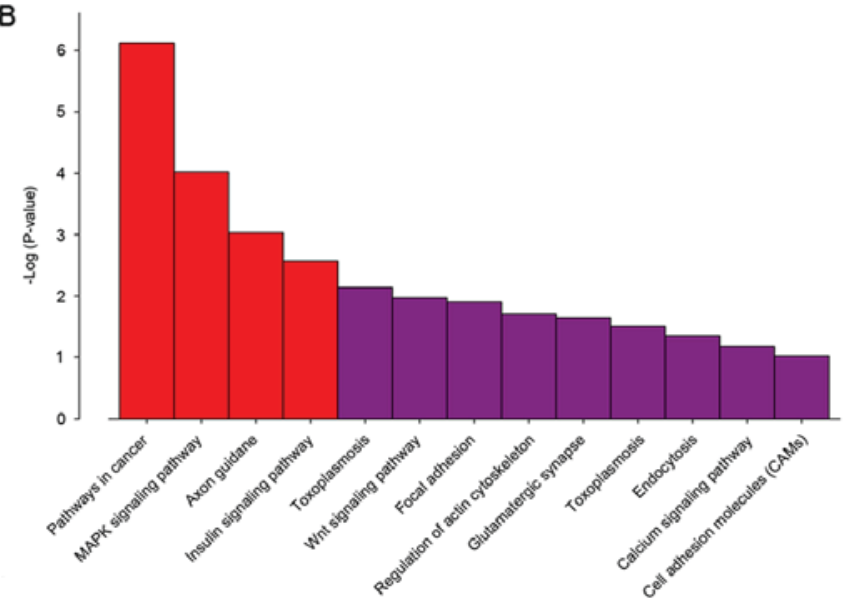

Figure 3. (A) Heatmap of corresponding genes at different methylation sites. (B) Significant pathways of corresponding genes at different methylation sites.

ambivalent influences in cancer (28). RASSF genes are tumor suppressors and RASSF expression is decreased in various types of cancer (29). The results of the present QMSP experiment demonstrated that the methylation of the MLH, PTEN, RUNX, RASSF, CDH1, MGMT and P16 genes and the related genes had no obvious difference in 2D, 3D and Tis culture conditions (Fig. 4A and B).

\section{Discussion}

CRC has a high incidence and mortality rate worldwide (30). Studies have demonstrated that the occurrence rate of CRC in China has increased yearly and the rate will continue to increase with time $(31,32)$. At present, $\sim 1.25$ million worldwide have $\mathrm{CRC}$ and $>600,000$ patients will lose their life as a result each year (33). In human CRC, it has been demonstrated that DNA methylation of $\mathrm{CpG}$ islands is able to silence the gene when the methylation occurs in a promoter region (34). In normal cells, CG nucleotides have been identified in promoter regions of several tissue-specific genes with no change in the methylation pattern; however, in cancer cells, this pattern was altered (35). The present study aimed to explore the influence of culture method on DNA methylation in CRC.

First, human CRC DLD-1 cells were obtained and cultured at 2D, 3D and Tis stage cultures. The differentially methylated DNA in each sample was selected and the relationship between them was determined by PCA. Results demonstrated that the differentially methylated DNA in the three different samples was closely related. In order to determine groups of differentially methylated sites common in the three samples or belonging to one sample, a Venn diagram was used for intersection and union analysis with different comparisons. 
A

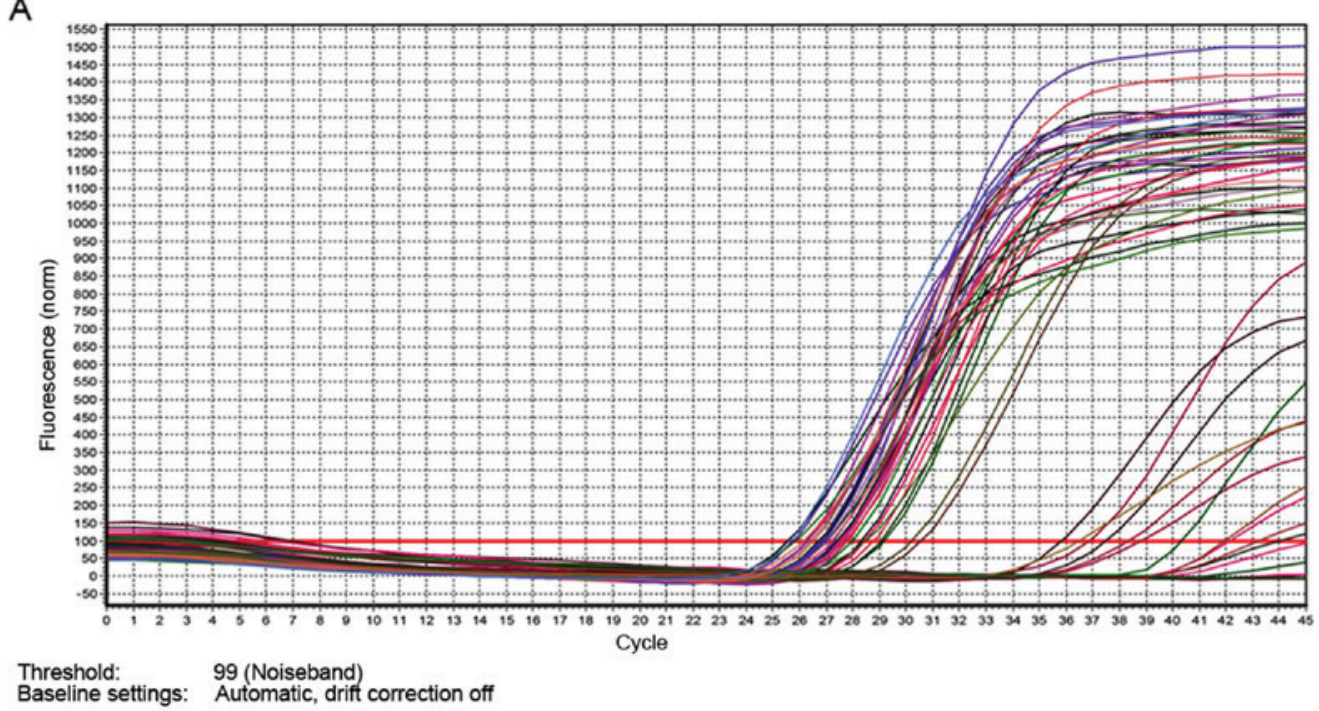

B

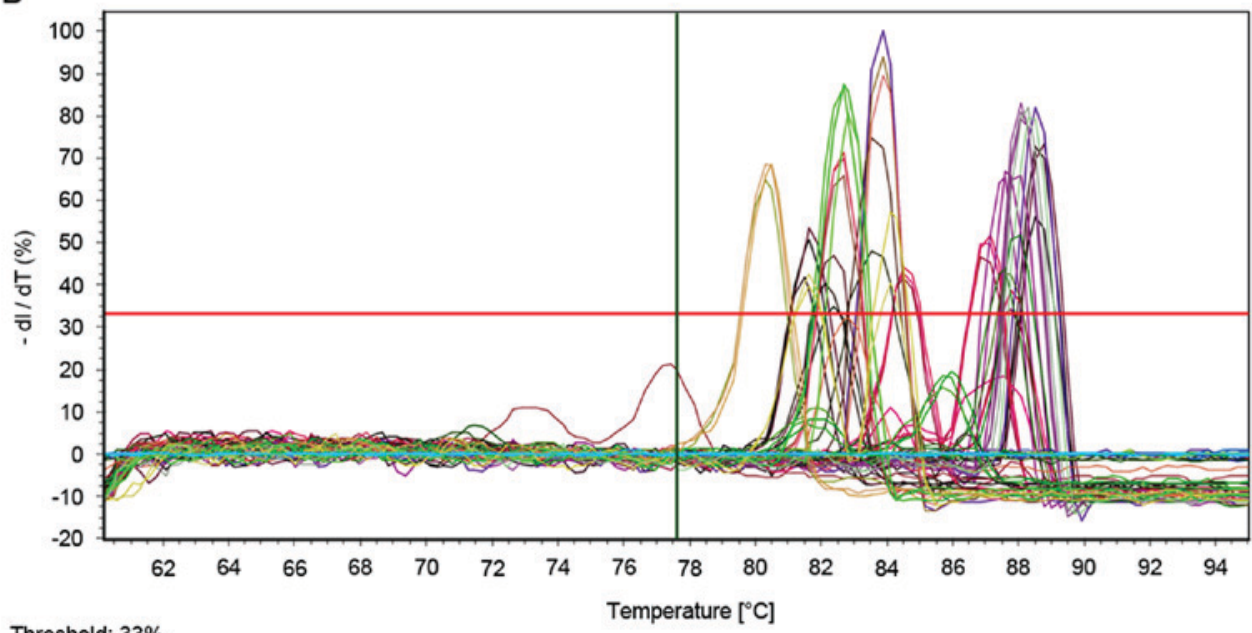

Figure 4. Quantitative methylation specific real-time polymerase chain reaction studying the methylation condition of mutL homolog, phosphatase and tensin homolog, runt-related transcription factor, Ras association family member, cadherin-1, O-6-methylguanine-DNA-methyltransferase and P16, and related genes. (A) Association between fluorescence and cycle. (B) Rate of relaxation varies with temperature. dl/dT, rate of relaxation.

Results identified that 23 differentially methylated sites were common among the three groups of samples, and the common sections presented high methylation in the three samples. Unsupervised clustering analysis was then used to explore the methylation status of $\mathrm{CpG}$ regions. Results demonstrated that $119 \mathrm{CpGs}$ presented different levels of methylation in the three groups of samples and $16 \mathrm{CpGs}$ all appeared to have a high methylation status in the three groups of samples. Previous research has investigated abnormal DNA methylation in promoters with a $\mathrm{CpG}$ region, and $\mathrm{CpG}$ region shores were reported have a key role in hiding the alteration of DNA methylation in human CRC (36). In the present study, scatter plots were created to compare all $\mathrm{CpG}$ sites among the DLD1-3D, DLD1-2D and DLD1-Tis groups and to analyze the different $\mathrm{CpG}$ locations in CRC cells cultured in 2D, 3D and Tis stage. Results demonstrated that methylation patterns of DLD1-3D and DLD1-2D were more similar than those of DLD1-3D and DLD1-Tis, and DLD1-Tis and DLD1-2D.

The results of GO indicated that differentially expressed genes were involved in molecular function, cellular component and biological function. KEGG pathway analysis creates manually curated pathway maps that present content on biological networks in graphical forms (37). The present results demonstrated that genes were enriched in 13 pathways, and four of these pathways were more evident than the rest. These pathways included cancer pathways, the MAPK signaling pathway, axon guidance and the insulin signaling pathway. PTEN is a tumor suppressor that may negatively affect the phosphatidylinositol-3 kinase/protein kinase B signaling pathway (38). In CRC, abnormal expression of PTEN is useful for the damage responses to cetuximab (39). Furthermore, PTEN downregulation is related to liver metastasis and low survival rate in CRC (40). RUNX may regulate a variety of biological processes, such as growth and differentiation of lymphocytes and hematopoietic cells (41). In CRC cells, RUNX2 may regulate the transcription of a metastatic gene, osteopontin (42). RASSF gene family genes have been reported to be epigenetically silenced with promoter methylation (43). Ras proteins have an important role in human cancer and may activate mutations in Ras, which occur in $\sim 30 \%$ of tumors (44). 
To explore whether the different cell culture methods had an effect on important genes, a QMSP experiment was performed in the present study. Results demonstrated that the methylation of the MLH, PTEN, RUNX, RASSF, CDH1, MGMT and P16 genes and the related genes had no obvious difference in the 2D, 3D and Tis culture conditions.

Considering the results and discussion above, in conclusion, DNA methylation was associated with the development of CRC; however, this was not altered under 2D, 3D or Tis culture conditions. However, previous research has demonstrated that DNA methylation and gene expression in squamous cell carcinoma had significant differences between 2D and 3D culture systems (45). Compared with squamous cell carcinoma, CRC may have particular characteristics due to a unique microenvironment. It is extremely complex to study the molecular mechanisms of CRC in a tumor model in situ; therefore, 3D cell culture, may replace animal models as a novel experimental method to study the progression of CRC. However, the effects of different culture methods on other cancer types requires further research.

\section{References}

1. Lobert VH, Mouradov D and Heath JK: Focusing the spotlight on the zebrafish intestine to illuminate mechanisms of colorectal cancer. Adv Exp Med Biol 916: 411-437, 2016.

2. Jemal A, Bray F, Center MM, Ferlay J, Ward E and Forman D: Global cancer statistics. CA Cancer J Clin 61: 69-90, 2011.

3. Girard P, Ducreux M, Baldeyrou P, Rougier P, Le Chevalier T, Bougaran J, Lasser P, Gayet B, Ruffié P and Grunenwald D: Surgery for lung metastases from colorectal cancer: Analysis of prognostic factors. J Clin Oncol 14: 2047-2053, 1996.

4. Van Cutsem E, Köhne CH, Hitre E, Zaluski J, Chang Chien CR, Makhson A, D'Haens G, Pintér T, Lim R, Bodoky G, et al: Cetuximab and chemotherapy as initial treatment for metastatic colorectal cancer. N Engl J Med 360: 1408-1417, 2009.

5. Jiang W, Wang PG, Zhan Y and Zhang D: Prognostic value of p16 promoter hypermethylation in colorectal cancer: A meta-analysis. Cancer Invest 32: 43-52, 2014.

6. Zou HZ, Yu BM, Wang ZW, Sun JY, Cang H, Gao F, Li DH, Zhao R, Feng GG and Yi J: Detection of aberrant p16 methylation in the serum of colorectal cancer patients. Clin Cancer Res 8: 188-191, 2002.

7. Merlo A, Herman JG, Mao L, Lee DJ, Gabrielson E, Burger PC, Baylin SB and Sidransky D: 5' CpG island methylation is associated with transcriptional silencing of the tumour suppressor p16/CDKN2/MTS1 in human cancers. Nat Med 1: 686-692, 1995.

8. Shen L, Kondo Y, Rosner GL, Xiao L, Hernandez NS, Vilaythong J, Houlihan PS, Krouse RS, Prasad AR, Einspahr JG, et al: MGMT promoter methylation and field defect in sporadic colorectal cancer. J Natl Cancer Inst 97: 1330-1338, 2005.

9. Müller HM, Oberwalder M, Fiegl H, Morandell M, Goebel G, Zitt M, Mühlthaler M, Ofner D, Margreiter R and Widschwendter M: Methylation changes in faecal DNA: A marker for colorectal cancer screening? Lancet 363: 1283-1285, 2004.

10. Herman JG, Graff JR, Myöhänen S, Nelkin BD and Baylin SB: Methylation-specific PCR: A novel PCR assay for methylation status of CpG islands. Proc Natl Acad Sci USA 93: 9821-9826, 1996.

11. Deaton $\mathrm{AM}$ and Bird $\mathrm{A}: \mathrm{CpG}$ islands and the regulation of transcription. Genes Dev 25: 1010-1022, 2011.

12. Costello JF, Frühwald MC, Smiraglia DJ, Rush LJ, Robertson GP, Gao X, Wright FA, Feramisco JD, Peltomäki P, Lang JC, et al: Aberrant CpG-island methylation has non-random and tumour-type-specific patterns. Nat Genet 24: 132-138, 2000.

13. Holmquist GP and Ashley T: Chromosome organization and chromatin modification: Influence on genome function and evolution. Cytogenet Genome Res 114: 96-125, 2006.

14. Jones PA and Takai D: The role of DNA methylation in mammalian epigenetics. Science 293: 1068-1070, 2001
15. Wistuba II, Mao L and Gazdar AF: Smoking molecular damage in bronchial epithelium. Oncogene 21: 7298-7306, 2002.

16. Chai $\mathrm{H}$ and Brown RE: Field effect in cancer-an update. Ann Clin Lab Sci 39: 331-337, 2009.

17. Coppedè F, Migheli F, Lopomo A, Failli A, Legitimo A, Consolini R, Fontanini G, Sensi E, Servadio A, Seccia M, et al: Gene promoter methylation in colorectal cancer and healthy adjacent mucosa specimens: Correlation with physiological and pathological characteristics, and with biomarkers of one-carbon metabolism. Epigenetics 9: 621-633, 2014.

18. Godugu C and Singh M: AlgiMatrix ${ }^{\mathrm{TM}}$-based 3D cell culture system as an in vitro tumor model: An important tool in cancer research. Methods Mol Biol 1379: 117-128, 2016.

19. Hiler D, Chen X, Hazen J, Kupriyanov S, Carroll PA, Qu C, Xu B, Johnson D, Griffiths L, Frase S, et al: Quantification of retinogenesis in $3 \mathrm{D}$ cultures reveals epigenetic memory and higher efficiency in iPSCs derived from rod photoreceptors. Cell Stem Cell 17: 101-115, 2015.

20. Fidler IJ: The pathogenesis of cancer metastasis: The 'seed and soil' hypothesis revisited. Nat Rev Cancer 3: 453-459, 2003.

21. Schmittgen TD and Livak KJ: Analyzing real-time PCR data by the comparative C(T) method. Nat Protoc 3: 1101-1108, 2008.

22. Livak KJ and Schmittgen TD: Analysis of relative gene expression data using real-time quantitative PCR and the 2(-Delta Delta C(T)) method. methods 25: 402-408, 2001.

23. Bolstad BM,Irizarry RA, Åstrand M and Speed TP: A comparison of normalization methods for high density oligonucleotide array data based on variance and bias. Bioinformatics 19: 185-193, 2003.

24. Ma CH, Lv Q, Cao Y, Wang Q, Zhou XK, Ye BW and Yi CQ: Genes relevant with osteoarthritis by comparison gene expression profiles of synovial membrane of osteoarthritis patients at different stages. Eur Rev Med Pharmacol Sci 18: 431-439, 2014.

25. Bro R and Smilde AK: Principal component analysis. Anal Met 6: 2812-2831, 2014.

26. Rencher AC: Principal component analysis. Met Multi Anal, Second Edition: 380-407, 2002.

27. Stambolic V, Suzuki A, De La Pompa JL, Brothers GM, Mirtsos C, Sasaki T, Ruland J, Penninger JM, Siderovski DP and Mak TW: Negative regulation of PKB/Akt-dependent cell survival by the tumor suppressor PTEN. Cell 95: 29-39, 1998.

28. Blyth K, Cameron ER and Neil JC: The RUNX genes: Gain or loss of function in cancer. Nat Rev Cancer 5: 376-387, 2005.

29. Allen NP, Donninger H, Vos MD, Eckfeld K, Hesson L, Gordon L, Birrer MJ, Latif F and Clark GJ: RASSF6 is a novel member of the RASSF family of tumor suppressors. Oncogene 26: 6203-6211, 2007.

30. Atkin WS, Edwards R, Kralj-Hans I, Wooldrage K, Hart AR, Northover JM, Parkin DM, Wardle J, Duffy SW and Cuzick J; UK Flexible Sigmoidoscopy Trial Investigators: Once-only flexible sigmoidoscopy screening in prevention of colorectal cancer: A multicentre randomised controlled trial. Lancet 375: 1624-1633, 2010

31. Dai Z, Zheng RS, Zou XN, Zhang SW, Zeng HM, Li N and Chen WQ: Analysis and prediction of colorectal cancer incidence trend in China. Zhonghua Yu Fang Yi Xue Za Zhi 46: 598-603, 2012 (In Chinese).

32. Ni S, Peng J, Huang D, Xu M, Wang L, Tan C, SUN H, Cai S and Sheng W: HER2 overexpression and amplification in patients with colorectal cancer: A large-scale retrospective study in Chinese population. Am Society Clin Oncol, 2017.

33. Mu WP, Wang J, Niu Q, Shi N and Lian HF: Clinical significance and association of RUNX3 hypermethylation frequency with colorectal cancer: A meta-analysis. Onco Targets Ther 7: 1237-1245, 2014.

34. Weisenberger DJ, Siegmund KD, Campan M, Young J, Long TI, Faasse MA, Kang GH, Widschwendter M, Weener D, Buchanan D, et al: CpG island methylator phenotype underlies sporadic microsatellite instability and is tightly associated with BRAF mutation in colorectal cancer. Nat Genet 38: 787-793, 2006.

35. Yuan J, Luo RZ, Fujii S, Wang L, Hu W, Andreeff M, Pan Y, Kadota M, Oshimura M, Sahin AA, et al: Aberrant methylation and silencing of ARHI, an imprinted tumor suppressor gene in which the function is lost in breast cancers. Cancer Res 63: 4174-4180, 2003

36. Irizarry RA, Ladd-Acosta C, Wen B, Wu Z, Montano C, Onyango P, Cui H, Gabo K, Rongione M, Webster M, et al: The human colon cancer methylome shows similar hypo- and hypermethylation at conserved tissue-specific $\mathrm{CpG}$ island shores. Nat Genet 41: 178-186, 2009. 
37. Zhang JD and Wiemann S: KEGGgraph: A graph approach to KEGG PATHWAY in R and bioconductor. Bioinformatics 25: 1470-1471, 2009

38. Arico S, Petiot A, Bauvy C, Dubbelhuis PF, Meijer AJ, Codogno P and Ogier-Denis E: The tumor suppressor PTEN positively regulates macroautophagy by inhibiting the phosphatidylinositol 3-kinase/protein kinase B pathway. J Biol Chem 276: 35243-35246, 2001

39. Perrone F, Lampis A, Orsenigo M, Di Bartolomeo M, Gevorgyan A, Losa M, Frattini M, Riva C, Andreola S, Bajetta E, et al: PI3KCA/PTEN deregulation contributes to impaired responses to cetuximab in metastatic colorectal cancer patients. Ann Oncol 20: 84-90, 2009.

40. Sawai H, Yasuda A, Ochi N, Ma J, Matsuo Y, Wakasugi T, Takahashi H, Funahashi H, Sato M and Takeyama H: Loss of PTEN expression is associated with colorectal cancer liver metastasis and poor patient survival. BMC Gastroenterol 8: 56, 2008.

41. Miyazono K, Maeda S and Imamura T: Coordinate regulation of cell growth and differentiation by TGF-beta superfamily and Runx proteins. Oncogene 23: 4232-4237, 2004.
42. Wai PY, Mi Z, Gao C, Guo H, Marroquin C and Kuo PC: Ets-1 and runx2 regulate transcription of a metastatic gene, osteopontin, in murine colorectal cancer cells. J Biol Chem 281: 18973-18982, 2006.

43. Djos A, Martinsson T, Kogner P and Carén H: The RASSF gene family members RASSF5, RASSF6 and RASSF7 show frequent DNA methylation in neuroblastoma. Mol Cancer 11: 40, 2012.

44. van der Weyden L and Adams DJ: The Ras-association domain family (RASSF) members and their role in human tumourigenesis. Biochim Biophys Acta 1776: 58-85, 2007.

45. DesRochers TM, Shamis Y, Alt-Holland A, Kudo Y, Takata T, Wang G, Jackson-Grusby L and Garlick JA: The 3D tissue microenvironment modulates DNA methylation and E-cadherin expression in squamous cell carcinoma. Epigenetics 7: 34-46, 2012.

This work is licensed under a Creative Commons Attribution-NonCommercial-NoDerivatives 4.0 International (CC BY-NC-ND 4.0) License. 